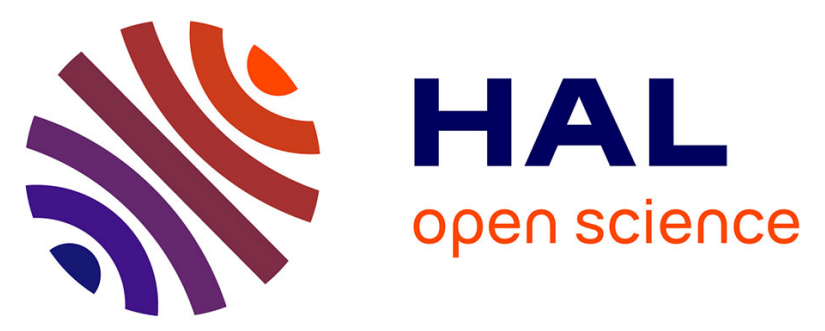

\title{
Direct reuse of electronic plastic scraps from computer monitor and keyboard to direct stem cell growth and differentiation
}

Pujiang Shi, Chiew Kei Tan, Zhuoran Wu, Jean-Christophe Gabriel, Madhavi Srinivasan, Jong-Min Lee, Chor Yong Tay

\section{To cite this version:}

Pujiang Shi, Chiew Kei Tan, Zhuoran Wu, Jean-Christophe Gabriel, Madhavi Srinivasan, et al.. Direct reuse of electronic plastic scraps from computer monitor and keyboard to direct stem cell growth and differentiation. Science of the Total Environment, 2022, 807 (3), pp.151085. 10.1016/j.scitotenv.2021.151085 . cea-03411164

\author{
HAL Id: cea-03411164 \\ https://hal-cea.archives-ouvertes.fr/cea-03411164
}

Submitted on 2 Nov 2021

HAL is a multi-disciplinary open access archive for the deposit and dissemination of scientific research documents, whether they are published or not. The documents may come from teaching and research institutions in France or abroad, or from public or private research centers.
L'archive ouverte pluridisciplinaire HAL, est destinée au dépôt et à la diffusion de documents scientifiques de niveau recherche, publiés ou non, émanant des établissements d'enseignement et de recherche français ou étrangers, des laboratoires publics ou privés. 


\section{Journal Pre-proof}

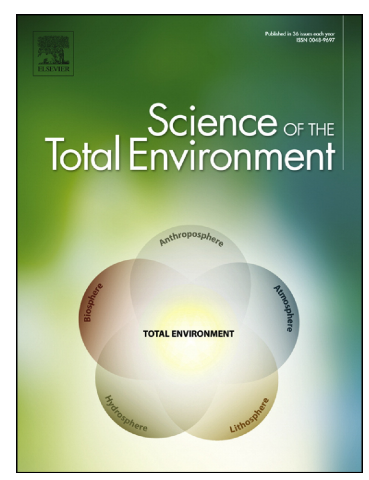

Pujiang Shi, Chiew Kei Tan, Zhuoran Wu, Jean-Christophe P. Gabriel, Madhavi Srinivasan, Jong-Min Lee, Chor Yong Tay

Direct reuse of electronic plastic scraps from computer monitor and keyboard to direct stem cell growth and differentiation

PII: $\quad$ S0048-9697(21)06163-5

DOI: $\quad$ https://doi.org/10.1016/j.scitotenv.2021.151085

Reference: $\quad$ STOTEN 151085

To appear in: $\quad$ Science of the Total Environment

Received date: $\quad 30$ August 2021

Revised date: $\quad 6$ October 2021

Accepted date: $\quad 15$ October 2021

Please cite this article as: P. Shi, C.K. Tan, Z. Wu, et al., Direct reuse of electronic plastic scraps from computer monitor and keyboard to direct stem cell growth and differentiation, Science of the Total Environment (2021), https://doi.org/10.1016/j.scitotenv.2021.151085

This is a PDF file of an article that has undergone enhancements after acceptance, such as the addition of a cover page and metadata, and formatting for readability, but it is not yet the definitive version of record. This version will undergo additional copyediting, typesetting and review before it is published in its final form, but we are providing this version to give early visibility of the article. Please note that, during the production process, errors may be discovered which could affect the content, and all legal disclaimers that apply to the journal pertain.

(C) 2021 Published by Elsevier B.V. 
Direct reuse of electronic plastic scraps from computer monitor and keyboard to direct stem cell growth and differentiation

Pujiang Shi ${ }^{1}$, Chiew Kei Tan ${ }^{1}$, Zhuoran Wu ${ }^{1}$, Jean-Christophe P. Gabriel ${ }^{1,2}$, Madhavi Srinivasan ${ }^{1,4}$, Jong-Min Lee ${ }^{1,3}$ and Chor Yong Tay ${ }^{1,4,5}$

1. Energy Research Institute, Nanyang Technological University, 1 Cleantech Loop, Singapore 637141

2. Université Paris-Saclay, CEA, CNRS, NIMBE, LICSEN, 91191, Gif-sur-Yvette, France

3. School of Chemical and Biomedical Engineering, Nanyang Technological University, 62 Nanyang Dr, Singapore 637459

4. School of Materials Science and Engineering, Nanyz" q I echnological University, 50 Nanyang Avenue, Singapore 639798

5. School of Biological Sciences, Nanyang Tect nc ingical University, 60 Nanyang Dr, Singapore 637551

Author of correspondence: Chor Yo Ị̣ ívy (email: cytay@ntu.edu.sg) 


\section{Abstract:}

Reuse of electronic wastes is a critical aspect for a more sustainable circular economy as it provides the simplest and most direct route to extend the lifespan of non-renewable resources. Herein, the distinctive surface and micro topographical features of computer electronic-plastic (E-plastic) scraps were unconventionally repurposed as a substrate material to guide the growth and differentiation of human adipose-derived mesenchymal stem cells (ADSCs). Specifically, the E-plastics were scavenged from discarded computer components such as light diffuser plate (polyacrylates), p.-matic sheet (polyethylene terephthalate), and keyboards (acrylonitrile butadiene styren`' v ere cleaned, sterilized, and systematically characterized to determine the identity $c t_{1} \cap$ plastics, chemical constituents, surface features, and leaching characteristics. Multi rara netric analysis revealed that all the E-plastics could preserve stem-cell phenotyp and maintain cell growth over 2 weeks, rivalling the performance of commercial tissu -cuiture treated plates as cell culture plastics. Interestingly, compared to commercial 1 , ue-culture treated plastics and in a competitive adipogenic and osteogenic differentiatic. environment, ADSCs cultured on the keyboard and light diffuser plastics favoured br-a $\iota^{-}$is formation while the grating-like microstructures of the prismatic sheet promoted : t cei's differentiation via the process of contact guidance. Our findings point to the real pussitılity of utilizing discarded computer plastics as a "waste-toresource" material to $\mathrm{prc}_{\mathrm{q}} \mathrm{r} . \mathrm{nme}$ stem cell fate without further processing nor biochemical modification, thus proviung an innovative second-life option for E-plastics from personal computers.

Keywords: Electronic-plastics; waste valorization; reuse; waste management; cell culture; stem cell differentiation 


\section{Introduction:}

Our relentless pursuit for economic growth and newer electronic goods has generated a vast number of electronic wastes (E-waste) (Shaikh et al. 2020). In 2019 alone, the global production of E-waste was estimated to be $53.6 \mathrm{Mt}$ and it is expected to grow to a striking 74.7 Mt by 2030 (Vanessa Forti 2020). Plastics is an integral component of electronics and accounts for $20 \%$ of E-waste by weight (Sahajwalla and Gaikwad 2018). The current documented recycling rates of E-plastics are thought to ho $7.4 \%$ at the global level (Vanessa Forti 2020) with the remaining uncaptured $\Xi$-vidstic waste stream mostly incinerated and/ or disposed in landfills. At least 15 dii rent types of electronic plastics (Eplastics) such as acrylonitrile butadiene styrene (Ab $\uparrow 1$ poly(methyl methacrylate) (PMMA), poly(vinyl chloride) (PVC), and polystyrene ( $\mathrm{P}$ ), imongst other highly recyclable plastics have been documented (Buekens and $V_{d}, y<\imath 14$ ). Nonetheless, there is a limit as to how many times the plastics can be recycled as the mechanochemical properties of the recycled plastic can decrease significantly is ? tunction of recycling cycles (Alhazmi et al. 2021). Additionally, the recycling of E plaitics is hampered by contamination and the complex compositional make-up of th^ Distic waste streams. Toxic metal-based colorants, stabiliser, catalysts, and brominatr. ' taune retardants (BFRs) were detected and measured in Eplastics at several orde - or magnitude higher than the currently permissible levels and may get released into the environment if not disposed properly. (Hahladakis et al. 2018, Singh et al. 2020) These toxic components can exert a broad spectrum of negative impacts on the environment and human health. In fact, a substantial number of recycled plastic products were found to contain toxic polybrominated diphenyl esters (PBDEs) and other BFRs (Gallen et al. 2014). Regardless, it is evident that E-plastics cannot be recycled indefinitely using the conventional mechanical and chemical pathways, and alternate waste management solutions should be sought to enable a holistic circular economy of E-plastics. 
On a global scale, the demand for innovative solutions to minimise $\mathrm{CO}_{2}$ emissions and waste valorisation is of increasing interest. Among the top priorities of the zero-waste hierarchy by the European Commission's Waste Framework Directive is to promote the reuse of plastic wastes (Billiet and Trenor 2020). Different from recycling, the reuse option offers the shortest path with minimum expenditure of energy to return the E-plastics into the "use" phase of the plastic value chain via pathways such as refurbish, remanufacture, or repurpose (Reike et al. 2018). Exercising the reuse option enables the immediate extension of the E-plastics lifespan and minimizes environmental pcimtion as a consequence of indiscriminate landfill disposal. Furthermore, by reusing th $\geqslant a_{1}$. carded scraps attuned for another function, the materials get a specific new life cyc e. F or instance, several innovative reuse of E-plastics for 3D printing (Gaikwad et al. $=u^{-1} 8$, Mikula et al. 2020), construction (Senthil Kumar and Baskar 2015, Dombe et a'. '¿2?0), and the automotive industry (Sahajwalla and Gaikwad 2018) have emerge $x_{1}$. rr cent years.

Owing to its abundance, ease of acquı ion, excellent self-renewable and differentiation properties, adipose-derived mesenchvrı. ㄱ stem cells (ADSCs) play a key role in the field of regenerative and reconstructive mad. ${ }^{\circ}$.ie. Numerous studies have shown the clinical utility of ADSCs-based therapies $\mathrm{fc}$ the treatment of diseases such as neurological disorders, cardiac ischemia, diabetes, and pone and cartilage diseases (Semenova et al. 2018, Dompe et al. 2019, Mazini e` ㄱ. วก _1). Moreover, ADSCs are broadly employed in basic scientific research including tissu modulation, tissue engineering, and development and drug testing, etc. (Zhang et al. 2020). In most cases, the cells are conventionally grown on smooth and sterile tissue culture plate made primarily using polystyrene (polystyrene TCP). However, biology is more than just a monotonous and flat terrain and it has been established that surface properties such as wettability, chemistry, topography, stiffness can profoundly influence fundamental cellular processes such as adhesion, spreading, proliferation, and differentiation (Amani et al. 2019, Paiva et al. 2020). 
In this study, we took a leaf out of the biomaterials playbook and repurposed E-plastics from personal computers (PC) as second life cell culture plastics for stem cells culture. Our approach is in part inspired by our earlier study, where we showed that E-plastics such as the prism, keyboard, diffuser, and screen protector can support the long-term growth of several human cell lines without any significant cytotoxic effects (Shi et al. 2020). Furthermore, the generation of research laboratory plastic wastes (including cell culture plastics) is substantial, which was estimated to be around 5.5 million tonnes in 2014 alone (Urbina et al. 2015). To put things into perspective, this coure significantly dwarfs the reported annual 18,5000 tonnes plastics flow 3D printing a| plic ttions (Li 2017). Therefore, the potential of E-plastics reuse for cell culture applicati in is posited to be at least on par with 3D printing. Specifically, we hypothesize E-plar “u- ssavenged from the discarded PC with distinct surface properties, namely, keyboard ligı ${ }^{+}$guide plate, screen diffuser could potentially be exploited to direct the growth $\varepsilon$ in $n f$, naviour of ADSCs. Three representative E-plastics namely, keyboard, light guid $>p^{\prime}$ tte, screen diffuser was examined. The screen diffuser sheets in the liquid-crystal $a_{1}$-nlays (LCDs) possess highly aligned prismatic ridges which could potentially guide cellulur al ynment (Leclech and Villard 2020, Shi et al. 2020). The diffuser sheets have smc $\jmath_{1}$. and flexible surfaces, while the surface of the keyboard casings is mechanically tnugı, and textured. The identity, chemical composition, surface properties of the E-plas ics vere systematically investigated. Our proof-of-concept studies revealed that the E-plas cs not only supported the long-term growth of ADSCs, but also retained the multilineage differentiation potential of the cells as indicated by robust expression of STRO-1 and CD166 stemness markers (Garcia et al. 2016). Intriguingly, using polystyrene TCP as a benchmark, osteogenic differentiation of ADSCs was enhanced on keyboard and diffuser E-plastics, while the prism sheet favours adipogenesis. Our findings unveil a first-of-a-kind and previously untapped potential of repurposing E-plastics as specialty substrates to renew and coax lineage-specific differentiation of mesenchymal stem cells. 


\section{Material and methods:}

\subsection{Materials and reagents:}

The E-plastics consisted of scraps from keyboards and LCDs were curated from Virogreen (Singapore) PTE Ltd. The samples were transported to the laboratory and manually dismantled using a screwdriver and penknife. In all cases, the electronics board can be easily separated from the plastics casing or components, thereby minimising crosscontamination of the metallic parts. The key buttons from the keyboard can be easily dislodged with the use of a flathead screwdriver. Meanwhile tho non-adhesive prism and diffuser sheets located in between the backlit and liquid $u^{\prime}{ }^{\prime \prime s}$ sals of the LCD screen were separated by hand. The plastic parts were subsequenı,' cut into a circular shape (radius = $11 \mathrm{~mm}$ ), and washed by double distilled water, followt $\uparrow r_{y}$ sonication and sterilization in $70 \%$ ethanol. The samples were air-dried in bioloç $\left|C^{\prime} \wedge\right|$ safety cabinet and stored under sterile conditions for further biological investic alı ns. ASC52telo, hTERT immortalized adiposederived mesenchymal stem cells (ADSCs, SCRC-4000) were purchased from American Type Culture Collection (ATCC). $A\ulcorner\bumpeq$ ?s were maintained in mesenchymal stem cell basal medium with the addition of a nıesı nchymal stem cell growth kit (PCS-500-030 and PCS500-040). Mouse anti-stro1 intin ndy (Stro-1) and rabbit anti-CD166 antibody (CD166) were purchased from Abcam 'nsuin, transferrin, sodium selenite, goat anti-mouse $\lg G(\mathrm{H}+\mathrm{L})$ highly cross-adsorbed s ssondary antibody, Alexa fluor plus 488, and chicken anti-rabbit IgG $(\mathrm{H}+\mathrm{L})$ cross-adsorbed secondary antibody, Alexa fluor 594 were purchased from ThermoFisher Scientific. Dexamethasone, ascorbic acid, $\beta$-glycerophosphate, indomethacin, and 3-isobutyl-1-methylxantine (IBMX) were purchased from Sigma-Aldrich.

The overall experimental design and workflow is illustrated in Schematic 1. 


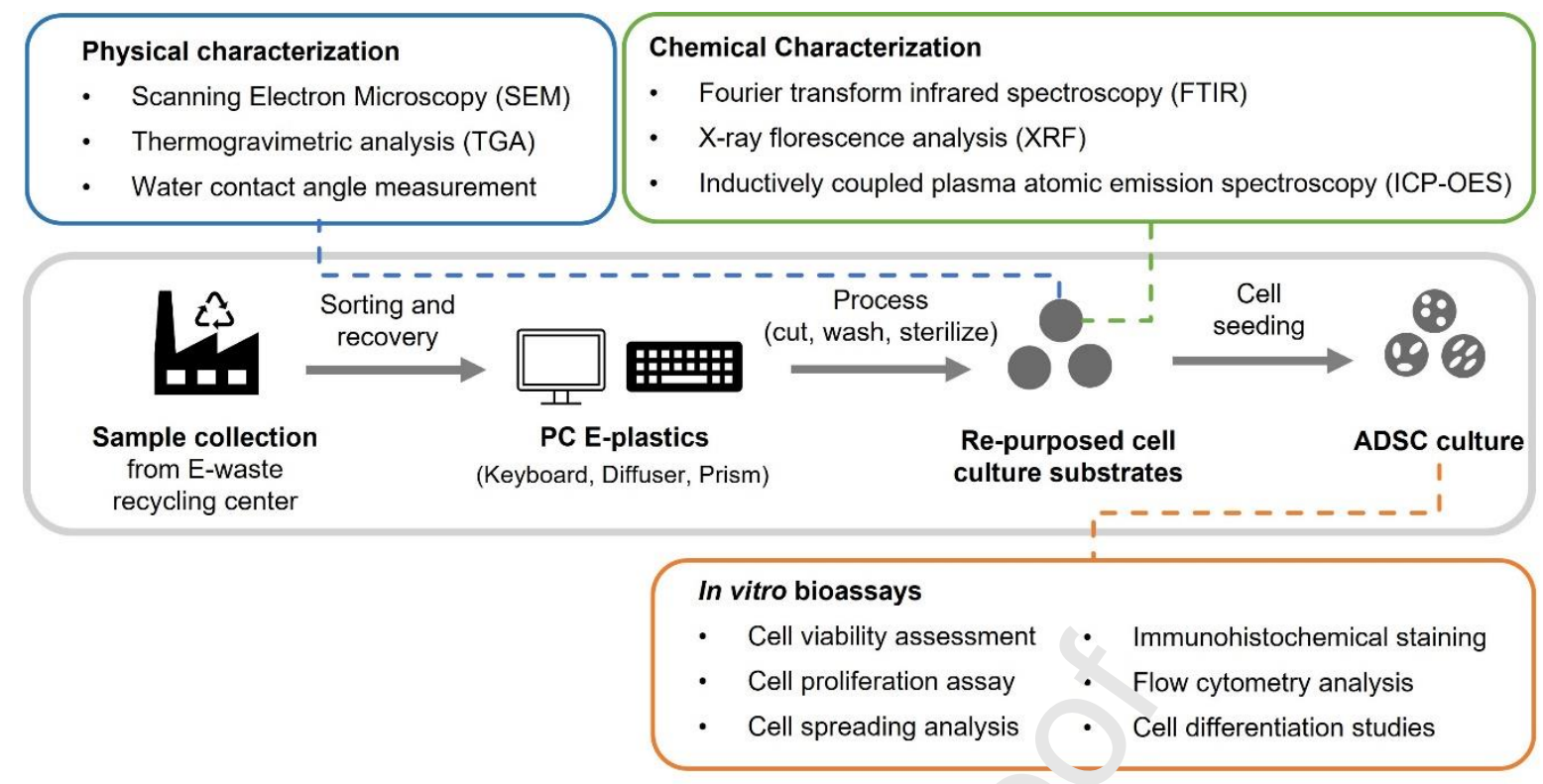

Schematic 1. Experimental design, workflow, and technly' 'es employed in this study.

\subsection{Fourier transform infrared spectroscopy $(\mathrm{F}, \mathrm{IR})$}

The E-plastics were evaluated using in :TIh spectrometer (Perkin Elmer Frontier), to identify the types of polymers and ir. rrganic/organic additives (Subramanian 2013). FTIR is an adaptable non-destructive vibri tir, $\therefore$-.. spectroscopic technique that can determine the molecular and functional group sresent in plastic polymers. FITR spectroscopy measures the infrared (IR) radiation awinrued by the plastic sample, thus enabling the study of its molecular composition. he -plastics were cut into small pieces, and further grounded into a fine powder, and th roughly blended with $\mathrm{KBr}$. Subsequently, the mixtures were compacted into pellets for examination. The samples were scanned 16 times respectively at an absorption wavelength ranging from 400 to $4000 \mathrm{~cm}^{-1}$ at a resolution of $2 \mathrm{~cm}^{-1}$.

\subsection{Water contact angle measurements}

Surface wettability was evaluated by the static water contact angle measurements. The contact angle was determined by the sessile drop method with optical contact angle measuring and contour analysis systems (DataPhysics Instruments, Germany). Ultra-pure water droplets of $0.25 \mu \mathrm{L}$ were applied to the E-plastic samples. Measurements were carried 
out at constant conditions (25ㅇ $\mathrm{C}$ and $60 \%$ humidity). The contact angle was calculated as an average of three measurements and was expressed as mean \pm standard deviation (SD).

\subsection{X-ray fluorescence (XRF) analysis}

Elemental analysis was carried out using a modified handheld X-ray fluorescence analyzer (Vanta C Series Handheld XRF analyzer, Olympus), following the previously published protocol (Shi et al. 2020). The handheld XRF analyzer was pre-calibrated by the manufacturer for plastic analysis. For safety reasons, the XRF analyzer was stabilized by a field stand during measurements, and the plastic samples merc placed on a silicon drift

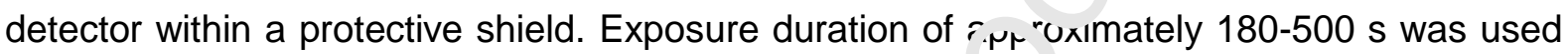
for each analysis, including a dwell time of $60 \mathrm{~s}$ in the $\mathrm{l}$ v energy range (30 kV and $66.67 \mu \mathrm{A}$ to measure $\mathrm{Cl}, \mathrm{Cr}$, and Ti elements) and main energy ro. Ige (50 kV and $40 \mu \mathrm{A}$ : all remaining elements measurements). The generated X-r iy s iectra were automatically deconvoluted and semi-quantified to determine the drv wigri elemental concentrations (parts per million, ppm).

\subsection{Inductively coupled plasma ai $\partial^{\prime} n$, emission spectroscopy (ICP-OES)}

The E-plastics samples incluning ieyboard, prism, and diffuser sheets were incubated in ADSC basal media, DMEl: an i competitive differentiation media respectively for 14 days. The volume ratio of $a_{1} \cdot n k$, to cell culture media is consistent with the ratio during cell culture and differentiatic:, studies. Briefly, the samples were completely submerged into cell culture media in securely sealed centrifuge tubes at $37^{\circ} \mathrm{C}$. Two weeks later, the supernatants were collected, filtered (syringe filter, Millipore), and stored at $4^{\circ} \mathrm{C}$ for future analysis via ICP-OES. The detection limit of the ICP-OES is $1 \mathrm{ppm}$. Polystyrene TCP were also analyzed by XRF and ICP-OES as control.

\subsection{Cell culture and seeding}

ADSCs were maintained in mesenchymal stem cell basal medium with the addition of a mesenchymal stem cell growth kit (PCS-500-030 and PCS-500-040). Fifty thousand $\left(5 \times 10^{4}\right)$ 
cells were seeded on each E-plastic and polystyrene TCP, and they were cultured at least 24 hours before cell viability assay and differentiation study. Meanwhile, the ADSCs on Eplastics and polystyrene TCP were cultured in basal media for 2 weeks for Stro- 1 and CD166 analysis. The cells were routinely replenished with fresh cell culture or differentiation medium every 3-4 days.

\subsection{Cell viability and proliferation assay}

$5 \times 10^{4}$ ADSCs were seeded on the E-plastics respectively, and the cells were maintained in stem cell growth media. Stem cells viability was monitored ' 'ciri the PrestoBlue assay in accordance with earlier studies (Yang et al. 2019, Shi et $a^{\prime} .2^{\prime} /<v$, Wang et al. 2020, Wang et al. 2021). Briefly, at predetermined time points (i.e., 1, 4, 7 days), the original cell culture media was removed from the E-plastic grown sten, ^r,ls samples. Thereafter, $1 \mathrm{ml} 10 \%$ Prestoblue (in basal medium) was added to th $ə$ e spective medium samples and mixed by pipetting. After $60 \mathrm{~min}$ of the incubatio' $\wedge$ ərı $\gamma, 200 \mu$ of the reaction mix was pipetted directly into a 96 well plate and the r duced Prestoblue signal was determined at fluorescence excitation/emission mזxi na of 560/590nm using a SpectraMax M2 microplate reader (Molecular Devices, USA'. C'lls cultured on conventional polystyrene TCP served as control.

\subsection{Scanning electron nicı गscope (SEM)}

The original plastic sai...ples of the keyboard, prism, and diffuser were sputter-coated with platinum and observed under thermionic SEM (JEOL 6360). The ADSCs seeded prism sheet at day 14 were fixed by $4 \%$ PBS buffered paraformaldehyde, and the cells were dehydrated by ethanol, and eventually dried in a critical point dryer (Tousimis Samdri-PVT3D). The dried samples were sputter-coated by platinum and observed under thermionic SEM (JEOL 6360). All the samples were observed under 5KV (accelerating voltage).

\subsection{Morphological analysis of ADSCs}


The ADSCs on the prism, diffuser, keyboard, and polystyrene TCP samples were fixed on day 7 and 14 respectively. The samples were permeabilized by $0.1 \%$ Triton X-100 for 5 mins and washed by $0.05 \%$ Tween-20/PBS three times. The permeabilized cells were stained by Alexa Fluor ${ }^{\mathrm{TM}} 594$ Phalloidin (ThermoFisher scientific), and the nucleus was stained by Hoechst 33258, Pentahydrate (ThermoFisher scientific). The stained cells on E-plastics were observed under a fluorescence microscope (Carl Zeiss).

\subsection{Stemness markers of ADSCs on E-plastics}

The ADSCs were seeded on the e-plastics and cultured in $\triangle L=C$ basal medium for two weeks. Subsequently, the cells were detached, centrifugf $i$, ₹ıı fixed by ice-cold methanol, and the cells were spun down to remove methanol. .or immunostaining, the cells were permeabilized by $0.1 \%$ Triton X-100 for 5 mins and $v$ : $x$, led by $0.05 \%$ Tween-20/PBS three times, then the samples were blocked by $1 \% \mathrm{k}$ o ir $\geqslant$ serum albumin (BSA). One hour later, the samples were incubated in $1 \% \mathrm{BSA}$ ov. itı? containing mouse monoclonal anti-STRO1 antibody (Abcam) and rabbit monocloı.? anti-CD166 antibody (Abcam) overnight. Subsequently, the samples were w's $w^{\circ}$ by PBS, and then they were incubated with Goat anti-mouse $\lg G(\mathrm{H}+\mathrm{L})$ highly crnss-c 'sorbed secondary antibody, Alexa fluor plus 488 , and

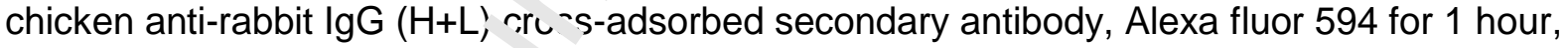
respectively. The samr:c = vere then eventually washed by PBS three times and resuspended in $1 \mathrm{ml} P \mathrm{P} ?$ and analyzed by a fluorescence microscope (excitation/emission: 495/519 nm and 591/614 nm, respectively) and flow cytometer (Guava easyCyte HT).

\subsection{Differentiation of ADSCs on E-plastics}

The osteogenic media was prepared by adding 10\% FBS, $0.01 \mu \mathrm{M}$ dexamethasone, 50 $\mu \mathrm{g} / \mathrm{mL}$ ascorbic acid, $10 \mathrm{mM}$ sodium $\beta$-glycerophosphate, $1 \%$ Penicillin/Streptomycin to the experimental culture media. Adipogenic Induction Media, consisting of DMEM-High glucose, supplemented with 10\% FBS, 1\% Penicillin/Streptomycin, $1 \mu \mathrm{M}$ dexamethasone, $1 \mu \mathrm{M}$ indomethacin, $500 \mu \mathrm{M}$ IBMX, $10 \mu \mathrm{g} / \mathrm{ml}$ insulin, $5.5 \mu \mathrm{g} / \mathrm{ml}$ transferring and $5 \mathrm{ng} / \mathrm{ml}$ sodium 
selenite. The competitive differentiation media were prepared by mixing adipogenic and osteogenic induction media at an equal volume ratio. Fifty thousand $\left(5 \times 10^{4}\right)$ cells were seeded on E-plastics and control, the cell-seeded samples were maintained in the mesenchymal stem cell basal medium (section 2.6) for 2-3 days for cell accommodation, then the cells on the respective E-plastic were cultured in the competitive differentiation media for two weeks. To quantify the differentiation of ADSCs towards osteogenic and adipogenic lineages, the cells on each plastic sample at week 1 and 2 were trypsinized, and the cells on each plastic sample were collected and resusper ided in basal media, and then they were allowed to attach on polystyrene TCP in 4 hour : S bsequently, the cells were fixed by $4 \%$ paraformaldehyde and stained by alizarin rea and oil red individually. The stained cells from each sample were observed under $i$. $?$ 1.iicroscope, the alizarin red and oil red positive cells were counted, and the pror,ortin of osteogenic and adipogenic differentiation of ADSCs was calculated and $\mathrm{F}^{\prime} \mathrm{O}_{i} \mathrm{~A}$.

\subsection{Data analysis}

All data were expressed as mean \pm s ch. naard deviation. Statistical analysis was performed by pairwise comparison of experim€nta.' categories using a two-tailed, unpaired Student's t-test and multiple comparisons uriny single-factor analysis of variance (ANOVA) and post hoc Tukey tests, using SPS. ₹táiistics version 22.0. A p-value of less than 0.05 is considered statistically significant.

\section{Results and discussion:}

\subsection{Characterization of E-plastics}

Figure 1A-C shows the pictographs of the discarded keyboard black pushbuttons, diffuser, and prism sheets obtained from the disposed liquid crystal displays (LCD) respectively. Both the keyboard and diffuser plastics presented a relatively flat and smooth surface under the SEM (Figure 1D-E). Conversely, the prism surface was revealed to be composed of highly aligned prismatic ridges of height approximated to be around $23 \mu \mathrm{m}$ and pitch length of 52 
$\mu \mathrm{m}$ (Figure 1F). Besides surface topographies, the wettability of a plastic surface (hydrophilicity and hydrophobicity) has also been highlighted as a critical regulator of protein adsorption and cell-material interaction (Song and Mano 2013). Therefore, we performed the static water contact angle measurement to determine the wetting property of the E-plastic. Generally, a moderate hydrophobicity supports cellular adhesion and growth, while surfaces with extreme hydrophilicity (contact angle $<5^{\circ}$ ) or hydrophobicity (contact angle $>150^{\circ}$ ) present an interface that is thermodynamically unfavourable for cells to anchor onto the substrate (Law 2015). This is because surfaces with exceptic nal hydrophilic or hydrophobic features can suppress serum protein adsorption, which i; a nsidered as an obligatory process to establish cell-substratum contact. Since cell spre ading and division are always proceeded by cell adhesion, the inability for the äin ru.t cells to "stick" to the material surface would be detrimental to cell health (Tay et $a^{\prime} .2 \iota^{1} 1$ ). In the case of the E-plastics, the measured water contact angles were $97.0 \pm f^{\prime}, 81.7 \pm 4.4^{\circ}$, and $60.0 \pm 2.5^{\circ}$ for the keyboard, diffuser, and prism groups esr ectively, which is well-within the cell-adhesive range (Figure 1G). 

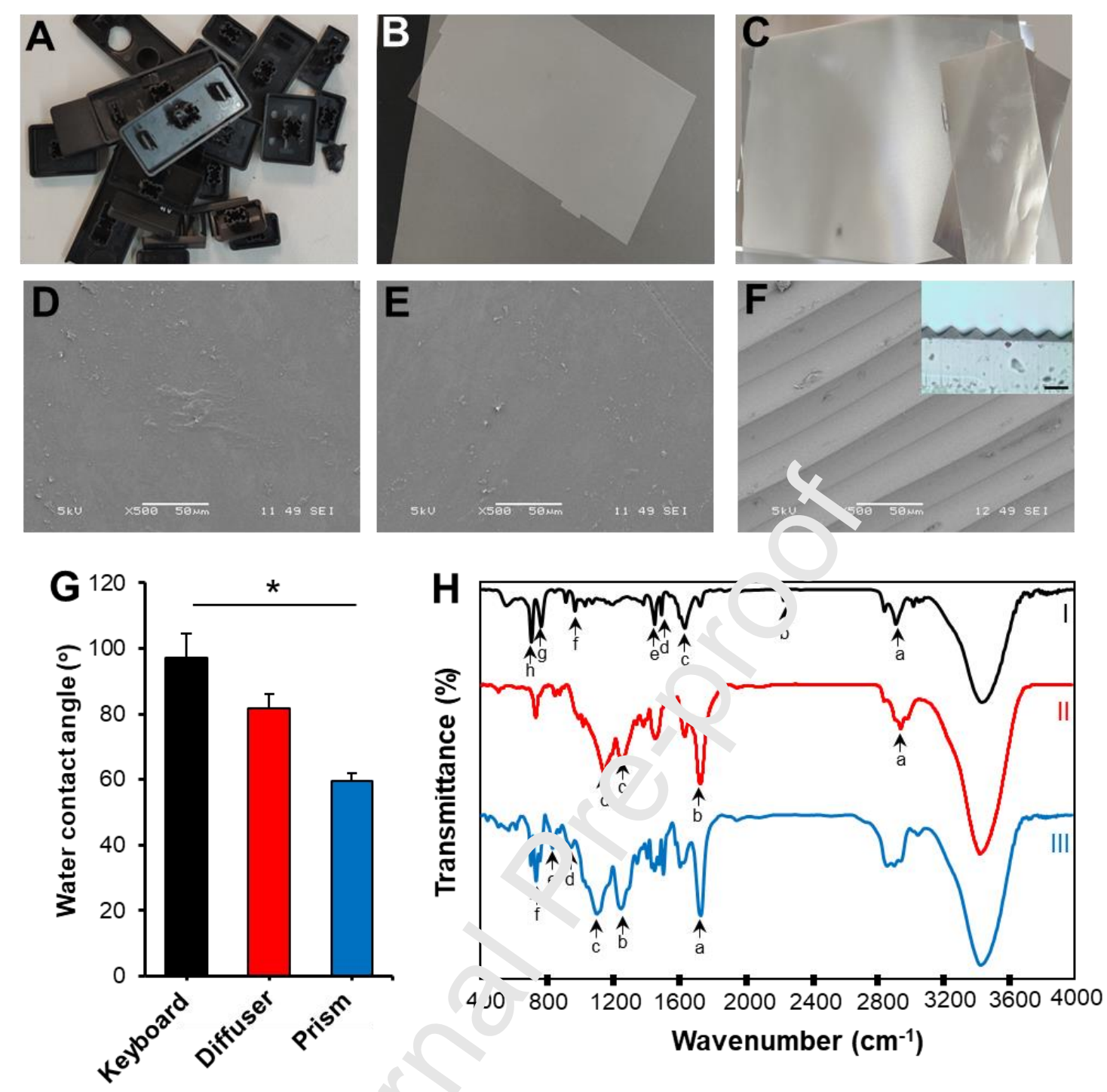

Figure 1. Representativ, $\mathrm{N}$ :tugraphs (A-C) and SEM images (D-F) of the keyboard, diffuser sheet, and prism sheel vere employed in this study. (Insert: cross-section of prism sheet, scale bar: $50 \mu \mathrm{m})$. (G) Static water contact angle measurements of the E-plastics. (H) FTIR spectra of the keyboard (I), diffuser (II), and prism sheet (III).

Since the E-plastics were produced by different manufactures using untraceable raw materials worldwide, therefore, it is pivotal to characterize and identify their polymer composition. Figure $\mathbf{1 H}$ shows the spectra of the corresponding E-plastics sample and the detected absorption peaks are summarised in Table S1. All FTIR spectra were crosschecked and verified with the KnowltAll IR Spectral Library as per the earlier report (Shi et al. 2020). Noteworthy, peak at $1602 \mathrm{~cm}^{-1}$ of the keyboard (Figure $\mathbf{1 H}-\mathbf{I}$ c) belongs to stretching 
vibration of $\mathrm{C}=\mathrm{C}$ double bond from butadiene units, while the peak at $1494 \mathrm{~cm}^{-1}$ (Figure $\mathbf{1 H}-\mathbf{I}$ d) represents the stretching vibration of the aromatic ring from styrene of acrylonitrile butadiene styrene (ABS), while the characteristic absorption peak at $2238 \mathrm{~cm}^{-1}$ (Figure 1H-I b) can be attributed to the $\mathrm{C} \equiv \mathrm{N}$ bond within $\mathrm{ABS}$ polymer chain ( $\mathrm{Li}$ et al. 2017). Conversely, the FTIR spectrum of the diffuser sheet (Figure $\mathbf{1 H}-\mathbf{I I} \mathbf{b}, \mathbf{c}$, and $\mathbf{d}$ ) revealed several distinct absorption bands at 1720,1158 , and $1253 \mathrm{~cm}^{-1}$, which correspond to the stretching vibration of carbonyl, ether, and epoxy groups of acrylic and methacrylic polymers respectively (Dzulkurnain et al. 2015). In the case of the prism sheet scmple (Figure 1H-III), the absorption peaks for $\mathrm{C}=\mathrm{O}$ in the carbonyl group (a, $1712 \mathrm{~L}-\ldots)$, and the $\mathrm{C}-\mathrm{O}$ stretching modes in alkanoate ester (b, $1241 \mathrm{~cm}^{-1}$ ) and ákoxy ether (c, $1094 \mathrm{~cm}^{-1}$ ) were detected(Prasad et al. 2011). Meanwhile, the peaks at ' 80 and $835 \mathrm{~cm}^{-1}$ (Figure 1H-III, d, and e) correspond to Si-O-Si and Si-OH of gli $\mathrm{Ss}$ (silica) respectively (Oh and Choi 2010). Therefore, it was deduced that the prisr.. sriet is made of glass-reinforced polyethylene terephthalate (PET).

Next, based on the RoHS and [rf (2009/48/EC, 2011/65/EU, and ¿1/6' ${ }^{\prime}$ 'EC), XRF was employed to detect representative toxic compounds of interests such i $s$ m inetals, brominated flame retardants. The presence of these toxic additives may pote itlai. $y$ hinder the reuse of these E-plastics as cell culture substrates. The evaluated elements included Chlorine $(\mathrm{Cl})$, Chromium (Cr), Manganese (Mn), Cobalt (Co), Nickel (Ni), Arsenic (As), Selenium (Se), Zirconium (Zr), Molybdenum (Mo), Cadmium $(\mathrm{Cd})$, Gold $(\mathrm{Au})$, Mercury $(\mathrm{Hg})$, Lead $(\mathrm{Pb})$, Bismuth (Bi), Calcium (Ca), Titanium (Ti), Zinc $(\mathrm{Zn})$, Bromine $(\mathrm{Br})$, Antimony $(\mathrm{Sb})$, Barium $(\mathrm{Ba})$, Iron $(\mathrm{Fe})$, Copper $(\mathrm{Cu})$ and Tin $(\mathrm{Sn})$. In general, the majority of the elements were undetectable in the E-plastics samples. However, as shown in Figure 2, elements such as $\mathrm{Ca}, \mathrm{Ti}, \mathrm{Zn}, \mathrm{Br}, \mathrm{Sb}$, and $\mathrm{Ba}$ were detected in the keyboard plastics. In addition, $\mathrm{Fe}, \mathrm{Cu}, \mathrm{Br}$, $\mathrm{Tin}, \mathrm{Sn}, \mathrm{Sb}$, and $\mathrm{Ba}$ were also found to be present in the prism sheet, while similar types of elements (except $\mathrm{Br}$ ) were observed in diffuser sheets. Further scrutiny of the XRF data revealed that several of the elements were detected 
at levels that exceed the limit set forth by RoHS and Directives of the European Parliament and the Council (2009/48/EC, 2011/65/EU, and 94/62/EC) standards (green arrows). Notably, the Sb content in all three E-plastics is considerably high. This is not unexpected as $\mathrm{Sb}_{2} \mathrm{O}_{3}$ is commonly added to plastics as inorganic flame retardants to withstand hightemperature usage (Nakashima et al. 2012). With the proposed cell culture application in mind, we next examined the leaching characteristics of the E-plastics in cell culture media at $37^{\circ} \mathrm{C}$. However, long-term (2 weeks) immersion of the E-plastics samples in the cell culture medium did not result in any appreciable metal leaching, as $\mathrm{tl}$ e concentration of the various metal species (i.e., Ba, Ni, Ag, Mn, $\mathrm{Cu}, \mathrm{Sb}, \mathrm{Cr}, \mathrm{Sr}, \mathrm{Zn}, \mathrm{Cd}, \mathrm{A}$; ar, $\mathrm{y} \mathrm{Ti}$, etc.) into the biological milieu were extremely low (less than 1ppm) (data not shc wn). This observation is consistent with our earlier studies, which showed that the outw'. n' migration of metal ions from various E-plastics was <1ppm (Mao et al. 2020, Shi et al 2Uこ?) and not deemed to be cytotoxic (Banfalvi 2011).

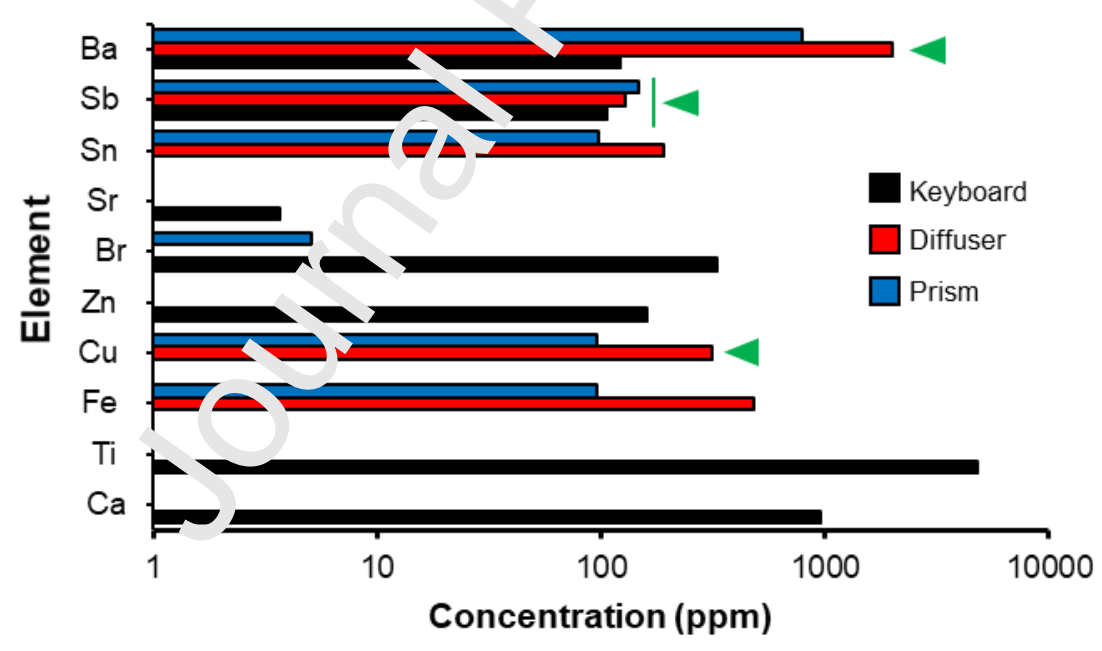

Figure 2. XRF analysis of E-plastics. Green arrow indicates elements that are detected at levels that exceeds the restriction limits of hazardous substances in accordance to 2009/48/EC, 2011/65/EU and 94/62/EC. Threshold limits of various metal species: Cu (156ppm), Zn (938ppm), As (3.8ppm), Sr (1125ppm), Sn (3750ppm), Sb (45ppm), Ba (1125ppm), $\mathrm{Pb}(13.5 p p m)$. 


\subsection{Self-renewing capacity of ADSCs on E-plastics}

ADSCs are non-specialized cells with the ability to self-renew and differentiate into cells of different tissue lineages, such as adipocytes and osteoblasts. ADSCs have emerged as one of the most widely utilized and studies stem cells due to their ease of retrieval and abundancy (Si et al. 2019). Besides its utility in cell-based therapies, ADSCs can also be applied as a powerful in vitro tool to advance our understanding of tissue development, establish physiologically relevant disease models to aid drın ac velopment, and elucidate important biological pathways for novel therapeutic inter vituris (Tay et al. 2013, Si et al. 2019, Yang et al. 2019). To fully exploit ADSCs, suitabı cell culture surfaces and conditions need to be optimized to promote cell growth while, ns;. Itaining the differentiation potential (stemness) of the stem cells. Therefore, we I $\mathrm{r}$ : ?xamined the ability of the sterilized Eplastics to support the adhesion and "ル"festion of ADSCs using the resazurin-based PrestoBlue assay. Polystyrene TCP was t. nployed as a control substrate to evaluate the suitability of the E-plastics for stem 'e suiture application. In agreement with the earlier data which shows limited metal ion eac'ing from the plastic samples, ADSCs displayed high viability (>95\%) for all the E-rlas 'ics group over 1 week, at the level that is comparable to the

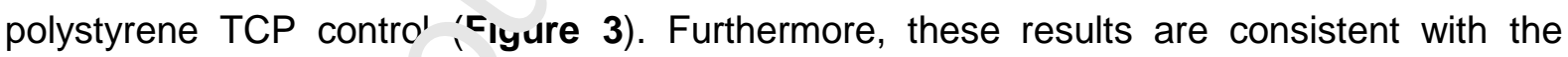
moderate wettability $\mathrm{u}$ : the E-plastics (Figure 1G), thereby permitting serum protein adsorption, cell attachment, and viability maintenance. This implies that the E-plastics are non-toxic and cytocompatible. 


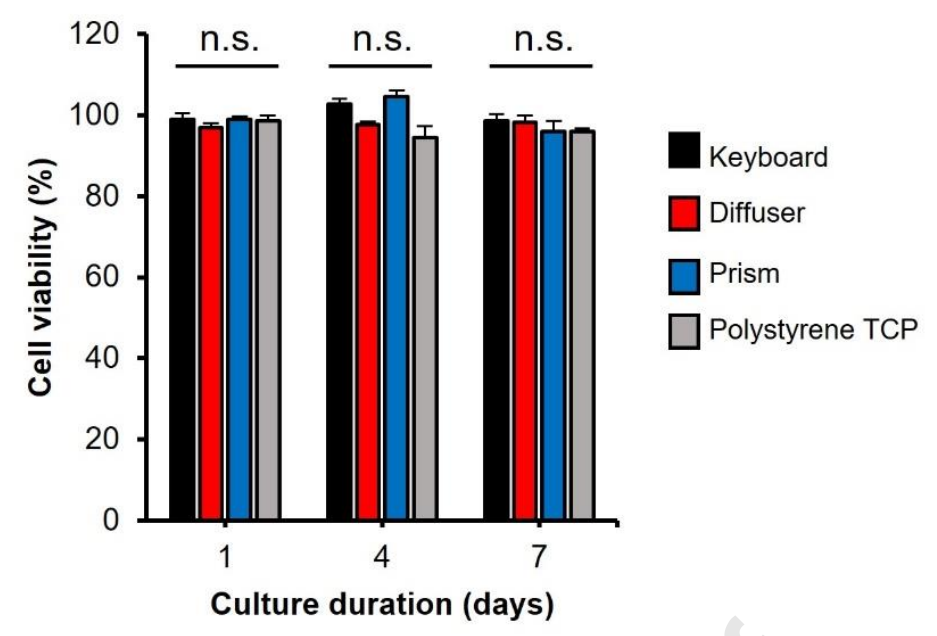

Figure 3. Quantitative cell viability assessment of ADSC, r'own on various E-plastics substrates. Polystyrene TCP serves as positive control Alı u'da are represented as mean \pm standard deviation from three experimental replicat s. $r$ s. denotes no statistical difference between experimental groups relative to the po'ys yrene TCP control. Statistical significance is determined at $p<0.05$.

Next, we ask if the long-term culture of $A D \subset C s$ on the E-plastics could result in the loss of ADSCs' differentiation capacity. F(i , is purpose, the cells were subjected to 2 weeks of culture on the E-plastics under 'aasa' growth condition and subsequently retrieved to probe for Stro-1 and CD166 exp:?ss:on using flow cytometry. Stro-1 and CD166 are wellestablished stemness m «n $>$ rs of mesenchymal stem cells, and their expression is indicative of the cells' multipotency (Huang et al. 2013, Mildmay-White and Khan 2017). As observed from the immunostaining images (Figure 4A), ADSCs displayed robust concomitant expression of Stro-1 and CD166 after 2 weeks of culture on the respective E-plastics. Consistently, flow cytometry analysis revealed that both the Stro- 1 and CD166 proteins were equally expressed on the ADSCs cultured on the keyboard, diffuser, prism, and polystyrene TCP individually. As can be seen in Figure 4B, there is only one population in each graph, and the intensity of the two stemness markers is comparable among the four samples. Collectively, not only we show that the E-plastics are non-cytotoxic, but also encourage the 
long-term adhesion and expansion of ADSCs while maintaining the mesenchymal stem cells phenotype.
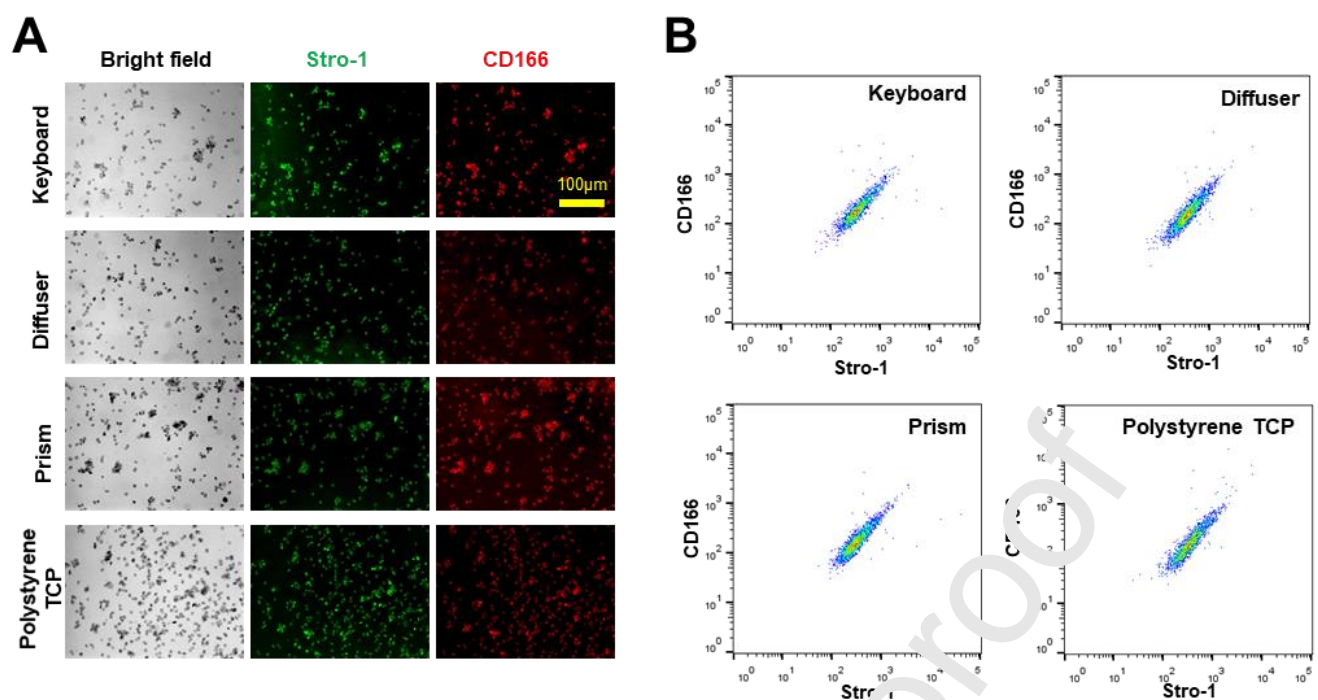

Figure 4. (A) Representative bright field and fl', ascence images of the recovered ADSCs counter-stained for Stro-1 (green) and $\mathrm{CD}^{1} \mathrm{G} 6$ 'red) after 2 weeks of culture in basal medium on the respective substrates. Polystyrem. TCP serves as the positive control. (B) Flow cytometry plot of ADSCs corresponding $\urcorner$ the respective experimental group indicating Stro$1(+)$ and CD166 (+) cells.

\subsection{Osteogenic and adipog-n/ı differentiation of ADSCs on E-plastics}

To investigate the inflı enc: of E-plastics surface features in directing ASDCs lineage commitment, we examinf $\mathrm{d}$ osteogenesis and adipogenesis simultaneously in cultures using a mixed differentiation media containing both osteogenic and adipogenic factors (Figure 5A). As shown in Figure 5B, ADSCs exhibit distinct morphologies on the various substrates after 7 days of culture. Whereas ADSCs on the keyboard, diffuser, and polystyrene TCP displayed the typical flatten and spread morphology, cells grown on the prismatic sheet were highly elongated and aligned in the direction of the groove edge likely to be due to the "contact guidance" phenomenon (Tay et al. 2011). After 14 days of culture, there was a significant increase in the number of cells attached to the respective substrates. This observation clearly shows that the E-plastics can support the mitotic activity of the cells, 
which corroborates the viability data and highlights the cytocompatibility of the E-plastic wastes. The cells on the keyboard and diffuser E-plastic remained flattened while the cells on the polystyrene TCP surface appear to be bigger, slightly polarized with well-developed stress fibers. Conversely, cells grown on the prism sheet remain elongated and appear to congregate along the long edges of the prisms. Indeed, upon closer inspection under the SEM, ADSCs were found preferentially attaching and elongating along the apex of the prismatic ridges and only a few cells could be observed in the grooves (Figure S1). This observation is consistent with an earlier study which showec that cell-substratum contacts were restricted to the tops of the ridges of silicon-based sub? tratı s with uniform grooves and ridges having pitch dimensions of 400-4000 nm (Karuri e al. ?004). A consequence of such adhesion pattern is that the cell spreading is sever,iy IInited spatially and can hinder the assembly of the cytoskeleton, as indicated by th.e c'iffuse/ fragmented F-actin staining (Figure 5B).

A
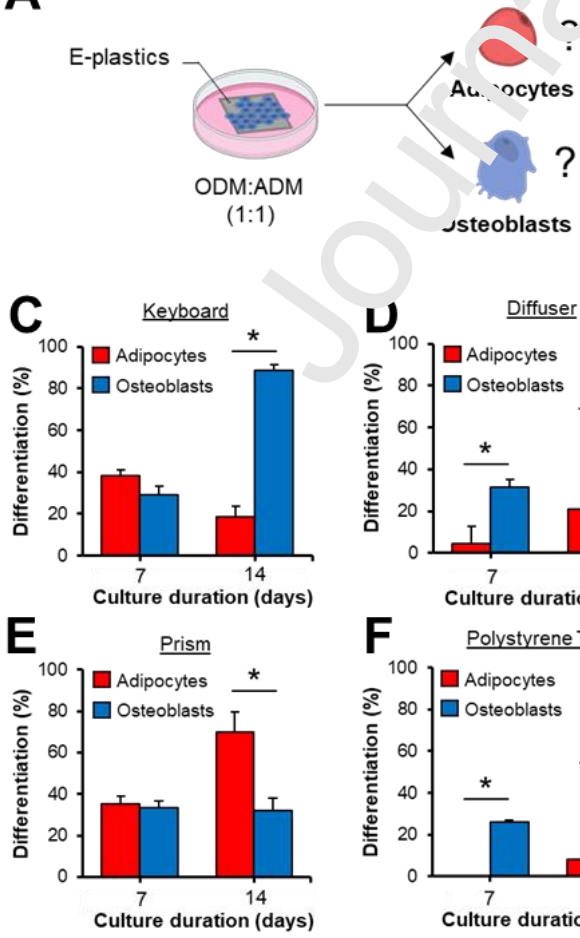
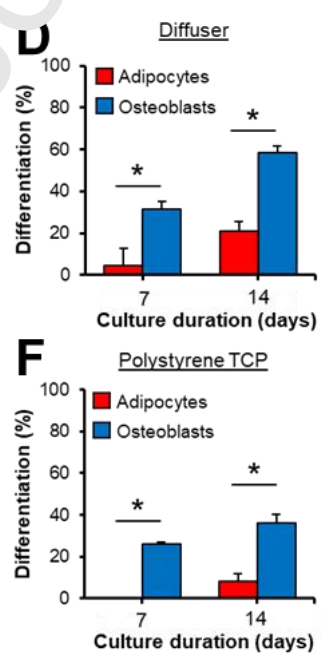

B
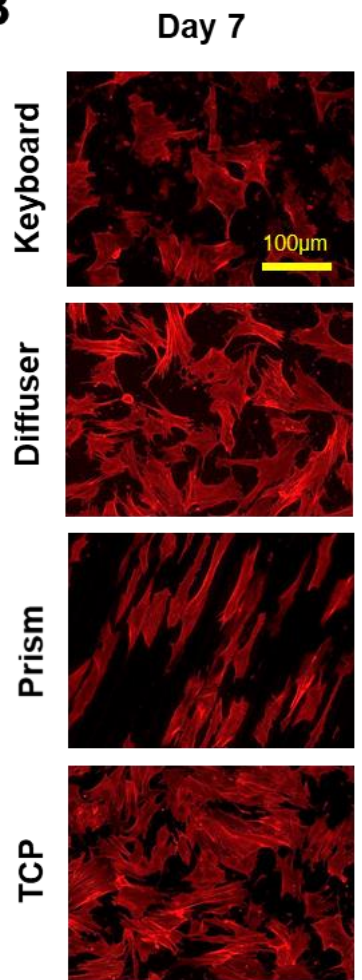

Day 14
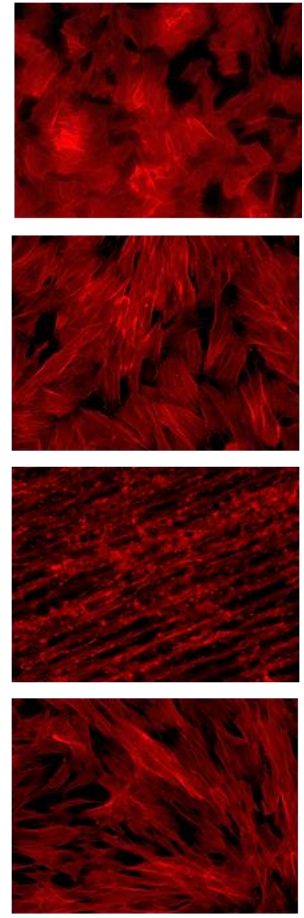
Figure 5. (A) Schematic illustrating the design of the experiment. ADSCs were cultured on the respective E-plastics consisting of a 1:1 ratio of osteogenic differentiation medium (ODM) and adipogenic differentiation medium (ADM) up to 2 weeks. Cells were then trypsinized and counter-stained for calcium and oil droplets as markers of osteoblasts and adipocytes respectively. (B) Representative fluorescence images of ADSCs on different substrates counter-stained for filamentous actin (red) to unveil the morphology and cytoskeleton development of the cells. Quantitative assessment to determine the percentage of osteoblasts and/ or adipocytes on the (C) keyboard, (D) riffuser, (E) prism, and (F) polystyrene TCP substrates. All data are represented as $r$ ieaı \pm standard deviation from three experimental replicates. ${ }^{*}$ denotes the statistical diffe ence between the compared experimental groups. Statistical significance is deterr.i. ? a at $p<0.05$.

As a measurement of osteogenic and adipor, =nc differentiation, ADSCs were counterstained with Alizarin Red S (for calcium) anci Jil red O (for lipids), corresponding to makers of bone and fat cells, respectively (Figu, - 5C-F). In general, all the tested E-plastics were observed to not only support osteng nesis and adipogenesis but also outperform the polystyrene TCP substrate in term - 0 : 'ifferentiation efficiency. Specifically, after 2 weeks of culture, the total number of ad: 'ocyies and osteoblasts was less than $45 \%$ in the polystyrene TCP group, while the numin or differentiated cells easily exceeds $80 \%$ on the E-plastics substrates. Unlike the sı.nr ih and flat surface presented on the polystyrene TCP, surface imperfections such as ,uughness, micro/ nano-features that are inherent to the E-plastics may contribute to the enhancement of osteogenic and adipogenic differentiation (McBeath et al. 2004, Tay et al. 2013, Tay et al. 2015, Shukla et al. 2016, Nicolas 2017, Khan et al. 2020). Furthermore, due to our competitive differentiation experimental design, the possibility of directing ADSCs to differentiate along a particular lineage on the various substrates can also be probed. Whereas the number of adipocytes and osteoblasts were comparable on the keyboard and prism E-plastics, there is a higher percentage of osteoblasts compared to adipocytes in the diffuser and polystyrene TCP groups after 7 days of culture. However, at 
the 14 days timepoint, all but the prism E-plastic displayed a tendency to favour osteogenesis. On average, the number of osteoblasts relative to the adipocytes was approximately 3 to 4 -fold larger. The osteo-directing effect of the keyboard E-plastics was particularly evident with almost $90 \%$ of the cells stained positive with Alizarin Red S, followed by the diffuser $(60 \%)$ and polystyrene TCP (40\%) groups. From the materials standpoint, our findings are in agreement with earlier studies which showed that ABS (base material for keyboard E-plastic) could enhance osteogenic differentiation and regeneration (Schmelzer et al. 2016) (Helguero et al. 2017). On the other hand, extens ve adipogenesis ( $70 \%)$ was observed on the prism plastics. Although traces amount of lea hed-out additives probably can play a potential role to modulate the ADSCs behavio $r, w \geqslant$ believe that this possibility is low. This notion is supported by the extremely low le $: c^{\prime}=1: 1 \mathrm{ppm}$ ) of metals ions detected in the cell culture leachate, as well as the on-par me.abc ${ }^{\prime i c}$ activity (Figure 3 ) and sustained expression of the stemness markers (Figur 3 in the ADSCs grown on the E-plastics relative to the polystyrene TCP control.

Both Stro-1 and CD166 are primitive stt. nness markers of MSCs (McMurray et al. 2011) and their expression strongly suggest thai ${ }^{+1}$, e pro-longed contact made between the ADSCs and the E-plastics has negligible : earıı in the absence of any soluble differentiation factors. Further mechanistic insighı into the preferential tissue-lineage differentiation phenomenon on the various plátic cubstrate can be better appreciated from the concept of mechanotransduction - the process of converting biophysical signals into a series of biochemical intracellular signalling cascades to regulate cellular fate and function (Tay et al. 2013, Nicolas 2017). Previous studies have implicated cell shape and cytoskeleton development as important determinants of stem cell differentiation (McBeath et al. 2004, Tay et al. 2015). It has been shown that cell spreading and formation of actin-based stress fiber could initiate a feed-forward loop involving the RhoA-ROCK signalling cascade to increase intracellular actomyosin mediated tension, thereby promoting osteogenesis (McBeath et al. 2004). Consistent with this paradigm, ADSCs grown on the keyboard and diffuser E-plastics 
were well spread, stress fibers were developed and the majority of the cells were directed towards an osteogenic lineage. In contrast, adipocyte differentiation is favoured in MSCs that are characterized with weak cell-material adhesion and under-developed actin cytoskeleton because of limited cell spreading (Liu et al. 2013, Shukla et al. 2016, Khan et al. 2020), as in the case of the cells grown on the prismatic sheet (McBeath et al. 2004).

\section{Conclusion:}

In summary, various E-plastics commonly found in an office setting were systematically characterized to repurpose them for stem cell culture applinainns. While XRF analysis revealed the presence of several toxic substances, it wa' ' in additives into the cell culture medium was negligible vver 2 weeks. Consistent with this observation and earlier report (Shi et al. 2020), In VIL $\cap$ c,udies showed that these E-plastics can support ADSCs adhesion and prolife at.o w while maintaining its multipotential differentiation properties. The ADSCs di $p_{1} y_{y} \iota^{\wedge}$ different adhesion patterns, morphologies, and cytoskeleton development, that are cuntingent on the surface roughness, wettability, and topographical features of the $=-$ lastics. Importantly, we demonstrated that E-plastic specific surface properties/ featı es -an profoundly influence and direct the differentiation of ADSCs along the osteogeni ${ }^{0}$, 7 dipogenic lineages. From the materials-standpoint, there are, however, two caver: to inis study. First, while the characterisation of the leches into the cell culture mediur, is extensive, it is by no means exhaustive. Second, although the ICP-OES data suggest that the leaching of metals into the cell culture medium $\left(37^{\circ} \mathrm{C}\right)$ is insignificant over 2 weeks, it does not exclude the possibility that the leaching of these additives may increase with time. Thus, future studies should focus on the integrated use of other characterization platforms such as high-resolution mass spectrometry to detect and identify other potentially toxic compounds that are uncovered in this study. Furthermore, future studies should also examine in greater detail the long-term outward migration profile of the plastic additives. Going forward, we recommend that there should be greater interdisciplinary efforts to create innovative E-plastics reuse solutions. Concerted attempts 
by materials scientists, biologists, biomedical engineers, and life science specialists should be directed to (i) ensure the quality of the E-plastics waste; (ii) expand the list of reusable Eplastics that are amenable for basic and advanced cell culture applications; and (iii) better appreciate the long-term effects of E-plastics exposure on the phenotype and performance of stem cells for potential therapeutic gain. Taken together, the findings presented in this study represent a significant paradigm shift in maximizing the value of E-plastics waste and open new "reuse" avenues for end-of-life E-plastics for various in vitro applications.

\section{Acknowledgment:}

This work was financially supported by a grant award fro ". "IV IU Singapore -CEA Alliance for Research in Circular Economy (SCARCE)", which is э joint lab set up between Nanyang Technological University (NTU, Singapore) and the ${ }^{*}$-or.ch Alternative Energies and Atomic Energy Commission (CEA, France). SCARC $E$ is supported by the National Research Foundation, Prime Minister's Office, Sily zрс-0, the Ministry of National Development, Singapore, and National Environment Ay-ncy, Ministry of the Environment and Water Resource, Singapore under the ClC II I tıe Waste Loop R\&D Initiative as part of the Urban Solutions \& Sustainability - Inten ratın Fund (award number USS-IF-2018-4).

\section{Reference:}

Alhazmi, H., F. H. r.'mcns',ur and Z. Aldhafeeri (2021). "Plastic Waste Management: A Review of Existing Life L.'cle Assessment Studies." Sustainability 13(10): 5340.

Amani, H., H. Arzaghi, M. Bayandori, A. S. Dezfuli, H. Pazoki-Toroudi, A. Shafiee and L. Moradi (2019). "Controlling Cell Behavior through the Design of Biomaterial Surfaces: A Focus on Surface Modification Techniques." Adv Mater Interfaces 6(13): 1900572 DOI: https://doi.org/10.1002/admi.201900572.

Banfalvi, G. (2011). Cellular Effects of Heavy Metals, Springer, Dordrecht.

Billiet, S. and S. R. Trenor (2020). "100th Anniversary of Macromolecular Science Viewpoint: Needs for Plastics Packaging Circularity." ACS Macro Letters 9(9): 1376-1390 DOI: 10.1021/acsmacrolett.0c00437.

Buekens, A. and J. Yang (2014). "Recycling of WEEE plastics: a review." J Mater Cycles Waste Manag 16(3): 415-434 DOI: https://10.1007/s10163-014-0241-2.

Dombe, S., A. B. Tapase, Y. M. Ghugal, B. A. Konnur and P. Akshay (2020). Investigation on the Use of E-Waste and Waste Plastic in Road Construction, Cham, Springer International Publishing. 
Dompe, C., G. Wąsiatycz, P. Mozdziak, M. Jankowski and B. Kempisty (2019). "Current clinical applications of adipose-derived stem cells in humans and animals." Medical Journal of Cell Biology 7(3): 105-111 DOI: https://10.2478/acb-2019-0014.

Dzulkurnain, N. A., S. A. Hanifah, A. Ahmad and N. S. Mohamed (2015). "Characterization of Random Methacrylate Copolymers Synthesized Using Free-Radical Bulk Polymerization Method." Int J Electrochem Sci 10: 84-92.

Gaikwad, V., A. Ghose, S. Cholake, A. Rawal, M. Iwato and V. Sahajwalla (2018). "Transformation of E-Waste Plastics into Sustainable Filaments for 3D Printing." ACS Sustain Chem Eng 6(11): 14432-14440 DOI: https://10.1021/acssuschemeng.8b03105.

Gallen, C., A. Banks, S. Brandsma, C. Baduel, P. Thai, G. Eaglesham, A. Heffernan, P. Leonards, P. Bainton and J. F. Mueller (2014). "Towards development of a rapid and effective non-destructive testing strategy to identify brominated flame retardants in the plastics of consumer products." Science of The Total Environment 491-492: 255-265 DOI: https://doi.org/10.1016/j.scitotenv.2014.01.074.

Garcia, C., L. C. C. Garcia, J. Henriques, M. R. Ely and P M. O. Garcia (2016). "Adipose tissue-derived stem cell autologous grafts: a new approach tc 2 , plication in the treatment of burn victims and reconstructive plastic surgery." Revista k rası jira de cirurgia 31: 417-423.

Hao, L., X. Fu, T. Li, N. Zhao, X. Shi, F. Cui, C. Du ana v. Wang (2016). "Surface chemistry from wettability and charge for the control of merenchymal stem cell fate through selfassembled monolayers." Colloids and Surfaces 느 Biointerfaces 148: 549-556 DOI: https://doi.org/10.1016/j.colsurfb.2016.09.027.

Helguero, C. G., V. M. Mustahsan, S. Parmar ¿ P',ntyala, J. L. Pfail, I. Kao, D. E. Komatsu

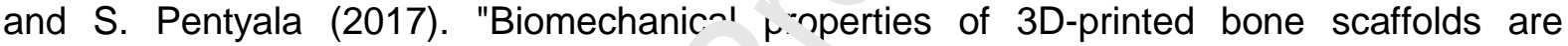
improved by treatment with CRF.." $\underline{J}$ Orthop Surg Res 12(1): 195 DOI: https://10.1186/s13018-017-0700-2.

Huang, S.-J., R.-H. Fu, W.-C. Shyu, S. D. Liu, G.-P. Jong, Y.-W. Chiu, H.-S. Wu, Y.-A. Tsou, C.-W. Cheng and S.-Z. Lin (2013). "Aı':nose-Derived Stem Cells: Isolation, Characterization, and Differentiation Potential." Cell Transplant 22(4): 701-709 DOI: https://10.3727/096368912X655 2\%.

Karuri, N. W., S. Liliensiek, A. '. Teixeira, G. Abrams, S. Campbell, P. F. Nealey and C. J. Murphy (2004). "Biological le . ^trı scale topography enhances cell-substratum adhesion of human corneal epitheliá. cells." $\quad \underline{J}$ Cell Sci 117(Pt 15): 3153-3164 DOI: https://10.1242/jcs.0114,

Khan, A. U., R. Qu, T. - 'an, J. Ouyang and J. Dai (2020). "A glance on the role of actin in osteogenic and adipogar,$c$ differentiation of mesenchymal stem cells." Stem Cell Res Ther 11(1): 283 DOI: https://10.1186/s13287-020-01789-2.

Law, K.-Y. (2015). "Water-surface interactions and definitions for hydrophilicity, hydrophobicity and superhydrophobicity." Pure Appl Chem 87(8): 759-765 DOI: https://doi:10.1515/pac-2014-1206.

Leclech, C. and C. Villard (2020). "Cellular and Subcellular Contact Guidance on Microfabricated Substrates." Front Bioeng Biotechnol 8(1198) DOI: https://10.3389/fbioe.2020.551505.

Li, J., F. Chen, L. Yang, L. Jiang and Y. Dan (2017). "FTIR analysis on aging characteristics of ABS/PC blend under UV-irradiation in air." Spectrochim Acta A Mol Biomol Spectrosc 184: 361-367 DOI: https://doi.org/10.1016/j.saa.2017.04.075.

Li, Z. (2017). "Application and Development of Chemical Materials in 3D Printing." Chemical Industry 35(2): 37-41 DOI: 10.3969/j.issn.1673-9647.2017.02.007. 
Liu, X., J. He, S. Zhang, X.-M. Wang, H.-Y. Liu and F.-Z. Cui (2013). "Adipose stem cells controlled by surface chemistry." $\mathrm{J}$ Tissue Eng Regen Med 7(2): 112-117 DOI: https://doi.org/10.1002/term.498.

Mao, S., W. Gu, J. Bai, B. Dong, Q. Huang, J. Zhao, X. Zhuang, C. Zhang, W. Yuan and J. Wang (2020). "Migration of heavy metal in electronic waste plastics during simulated

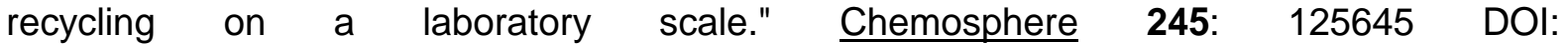
https://doi.org/10.1016/j.chemosphere.2019.125645.

Mazini, L., M. Ezzoubi and G. Malka (2021). "Overview of current adipose-derived stem cell (ADSCs) processing involved in therapeutic advancements: flow chart and regulation updates before and after COVID-19." Stem Cell Research \& Therapy 12(1): 1 DOI: https://10.1186/s13287-020-02006-w.

McBeath, R., D. M. Pirone, C. M. Nelson, K. Bhadriraju and C. S. Chen (2004). "Cell shape, cytoskeletal tension, and RhoA regulate stem cell lineage commitment." Dev Cell 6(4): 483495 DOI: 10.1016/s1534-5807(04)00075-9.

McMurray, R. J., N. Gadegaard, P. M. Tsimbouri, K. V. Burgr ss, '.. E. McNamara, R. Tare, K. Murawski, E. Kingham, R. O. Oreffo and M. J. Dalby (201i, "Nanoscale surfaces for the long-term maintenance of mesenchymal stem cell phenc typ€ and multipotency." Nat Mater 10(8): 637-644 DOI: 10.1038/nmat3058.

Mikula, K., D. Skrzypczak, G. Izydorczyk, J. Warch ıł, I'. Moustakas, K. Chojnacka and A. Witek-Krowiak (2020). "3D printing filament as a se ${ }^{\wedge}$ r.d life of waste plastics-a review." Environ Sci Pollut Res DOI: https://10.1007/s11356 020- i0657-8.

Mildmay-White, A. and W. Khan (2017). "Cfll ',ur ace Markers on Adipose-Derived Stem Cells: A Systematic Review." Curr Ctt. ${ }^{n}$ Cell Res Ther 12(6): 484-492 DOI: https://10.2174/1574888x11666160429-1 $22^{1} \overline{33}$.

Monchamp, A. (2000). The Evolution of lviaterials Used in Personal Computers. Second OECD Workshop on Environmentally ¿nund Management of Wastes Destined for Recovery Operations. Vienna, Austria.

Nakashima, E., A. Isobe, S. i. Ka'^ i. itai and S. Takahashi (2012). "Quantification of Toxic Metals Derived from Macroplas. : Litter on Ookushi Beach, Japan." Environ Sci Technol 46(18): 10099-10105 DOI: 10. : 21/es301362g.

Nicolas, A. (2017). "Cell arhesion mechanosensitivity, an active biological process." Phys Life Rev 22-23 DOI: http ...'1 ( . . 016/j.plrev.2017.10.001.

Nicolas, A. (2017). " $\mathrm{C}$ " adhesion mechanosensitivity, an active biological process: Comment on "Cellular $m_{t}$ shanosensing of the biophysical microenvironment: A review of the mathematical models o oiophysical regulation of cell responses" by Bo Cheng et al." Phys Life Rev 22-23: 123-126 DOI: 10.1016/j.plrev.2017.10.001.

Oh, T. and C. Choi (2010). "Comparison between SiOC thin films fabricated by using plasma enhanced chemical vapor deposition and $\mathrm{SiO} 2$ thin films by using Fourier transform infrared spectroscopy." J Korean Phys Soc 56(4): 1150-1155.

Paiva, S., P. Joanne, C. Migdal, E. L. Soler, Y. Hovhannisyan, A. Nicolas and O. Agbulut (2020). "Polyacrylamide Hydrogels with Rigidity-Independent Surface Chemistry Show Limited Long-Term Maintenance of Pluripotency of Human Induced Pluripotent Stem Cells on Soft Substrates." ACS Biomater Sci Eng 6(1): 340-351 DOI: https://10.1021/acsbiomaterials.9b01189.

Prasad, S. G., A. De and U. De (2011). "Structural and Optical Investigations of Radiation Damage in Transparent PET Polymer Films." Int J SpectrosC 2011: 810936 DOI: https://10.1155/2011/810936. 
Reike, D., W. J. V. Vermeulen and S. Witjes (2018). "The circular economy: New or Refurbished as CE 3.0? - Exploring Controversies in the Conceptualization of the Circular Economy through a Focus on History and Resource Value Retention Options." Resour Conserv Recycl 135: 246-264 DOI: https://doi.org/10.1016/j.resconrec.2017.08.027.

Sahajwalla, V. and V. Gaikwad (2018). "The present and future of e-waste plastics recycling." Curr Opin Green Sustain Chem 13: 102-107 DOI: https://doi.org/10.1016/j.cogsc.2018.06.006.

Schmelzer, E., P. Over, B. Gridelli and J. C. Gerlach (2016). "Response of Primary Human Bone Marrow Mesenchymal Stromal Cells and Dermal Keratinocytes to Thermal Printer Materials In Vitro." J Med Biol Eng 36(2): 153-167 DOI: https://10.1007/s40846-016-0118-z.

Semenova, E., M. Chroscinska-Krawczyk, M. P. Grudniak, T. Oldak and E. K. Machaj (2018). "Clinical application of AD-MSCs - A review." Journal of Pre-Clinical and Clinical Research 12(3): 100-105 DOI: https://10.26444/jpccr/94910.

Senthil Kumar, K. and K. Baskar (2015). "Recycling of E-plas:"? waste as a construction material in developing countries." $\mathrm{J}$ Mater Cycles Wastr $\mathrm{N}_{1}$ nag 17(4): 718-724 DOI: https://10.1007/s10163-014-0303-5.

Shaikh, S., K. Thomas and S. Zuhair (2020). "An explc"á'nrv study of e-waste creation and disposal: Upstream considerations." Resour Coni 'rv Recycl 155: 104662 DOI: https://doi.org/10.1016/j.resconrec.2019.104662.

Shi, P., Y. Wan, A. Grandjean, J.-M. Lee and C. I. Tay (2020). "Clarifying the in-situ cytotoxic potential of electronic waste Ni istics." Chemosphere: 128719 DOI: https://doi.org/10.1016/j.chemosphere.2020.1? ¿า 1 ?

Shukla, A., J. H. Slater, J. C. Culver, N. L Li-kinson and J. L. West (2016). "Biomimetic Surface Patterning Promotes Mesencı,'r al Stem Cell Differentiation." ACS Appl Mater Interfaces 8(34): 21883-21892 DOI: https:// ?.1021/acsami.5b08978.

Si, Z., X. Wang, C. Sun, Y. Kang, J. Xu, X. Wang and Y. Hui (2019). "Adipose-derived stem cells: Sources, potency, and implic ti $r_{1}$ - for regenerative therapies." Biomed Pharmacother 114: 108765 DOI: https://10.1016,". hic nlla.2019.108765.

Song, W. and J. F. Mano ( $\div 01$ !) "Interactions between cells or proteins and surfaces exhibiting extreme wєt+an ilities." Soft Matter 9(11): 2985-2999 DOI: https://10.1039/C3SM27739A.

Subramanian, M. N. (2( 13). Testing of Additives. Plastics Additives and Testing, Scrivener Publishing LLC: $177-\llcorner\urcorner$.

Tay, C. Y., S. A. Irvine F. Y. C. Boey, L. P. Tan and S. Venkatraman (2011). "Micro-/nanoengineered cellular responses for soft tissue engineering and biomedical applications." Small (Weinheim an der Bergstrasse, Germany) 7(10): 1361-1378 DOI: 10.1002/smll.201100046.

Tay, C. Y., S. A. Irvine, F. Y. C. Boey, L. P. Tan and S. Venkatraman (2011). "Micro-/Nanoengineered Cellular Responses for Soft Tissue Engineering and Biomedical Applications." Small 7(10): 1361-1378 DOI: https://doi.org/10.1002/smll.201100046.

Tay, C. Y., C. G. Koh, N. S. Tan, D. T. Leong and L. P. Tan (2013). "Mechanoregulation of stem cell fate via micro-/nano-scale manipulation for regenerative medicine." Nanomedicine (Lond) 8(4): 623-638 DOI: https://10.2217/nnm.13.31.

Tay, C. Y., Y.-L. Wu, P. Cai, N. S. Tan, S. S. Venkatraman, X. Chen and L. P. Tan (2015). "Bio-inspired micropatterned hydrogel to direct and deconstruct hierarchical processing of geometry-force signals by human mesenchymal stem cells during smooth muscle cell differentiation." NPG Asia Materials 7(7): e199-e199 DOI: 10.1038/am.2015.66. 
Tay, C. Y., Y.-L. Wu, P. Cai, N. S. Tan, S. S. Venkatraman, X. Chen and L. P. Tan (2015). "Bio-inspired micropatterned hydrogel to direct and deconstruct hierarchical processing of geometry-force signals by human mesenchymal stem cells during smooth muscle cell differentiation." NPG Asia Mater 7(7): e199-e199 DOI: https://10.1038/am.2015.66.

Urbina, M. A., A. J. Watts and E. E. Reardon (2015). "Environment: Labs should cut plastic waste too." Nature 528(7583): 479 DOI: 10.1038/528479c.

Vanessa Forti, C. P. B., Ruediger Kuehr, Garam Bel (2020). The Global E-waste Monitor 2020: Quantities, flows, and the circular economy potential, United Nations University (UNU)/United Nations Institute for Training and Research (UNITAR) - co-hosted SCYCLE Programme, International Telecommunication Union (ITU) \& International Solid Waste Association(ISWA), Bonn/Geneva/Rotterdam.

Wang, J. K., N. M. J. Cheam, S. A. Irvine, N. S. Tan, S. Venkatraman and C. Y. Tay (2020). "Interpenetrating Network of Alginate-Human Adipose Extracellular Matrix Hydrogel for Islet Cells Encapsulation." Macromol Rapid Commun 41(21): 2000275 DOI: https://doi.org/10.1002/marc.202000275.

Wang, J. K., Ç. Çimenoğlu, N. M. J. Cheam, X. Hu and L `. Tay (2021). "Sustainable aquaculture side-streams derived hybrid biocomposite $f_{*}, \mathrm{r}$ b $\mathrm{c}$ ne tissue engineering." Mater Sci Eng C 126: 112104 DOI: https://doi.org/10.1016/j.m‘ ec.žu21.112104.

Yang, H., N. M. J. Cheam, H. Cao, M. K. H. Lee, S. K. ¿ze, N. S. Tan and C. Y. Tay (2019). "Materials Stiffness-Dependent Redox Metabolic Run r.ugramming of Mesenchymal Stem Cells for Secretome-Based Therapeutic Angiogenєsis." Adv Healthc Mater 8(20): 1900929 DOI: https://doi.org/10.1002/adhm.201900929.

Yang, H., N. M. J. Cheam, H. Cao, M. K. ᄂ Lie, S. K. Sze, N. S. Tan and C. Y. Tay (2019). "Materials Stiffness-Dependent Redox Me abolic Reprogramming of Mesenchymal Stem Cells for Secretome-Based Therapeutic A. riogenesis." Adv Healthc Mater 8(20): e1900929 DOI: https://10.1002/adhm.2019009є?

Zhang, J., Y. Liu, Y. Chen, L. Yuan F. I_lu, J. Wang, Q. Liu and Y. Zhang (2020). "AdiposeDerived Stem Cells: Current Apnlic ations and Future Directions in the Regeneration of Multiple Tissues." Stem Cells Interna ${ }^{{ }^{i}}{ }^{\prime}$ nal 2020: 8810813 DOI: 10.1155/2020/8810813.

Zhang, X., J. Xu, Z. Lian, Z. 'ı and H. Yu (2015). Influence of microstructure on surface wettability. 2015 International Inriference on Advanced Mechatronic Systems (ICAMechS). 


\section{CRediT authorship contribution statement}

Pujiang Shi: Methodology, Validation, Formal analysis, Investigation, Writing - original draft, Writing - review \& editing, Visualization. Chiew Kei Tan and Zhuoran Wu: Formal analysis, Investigation. Jean-Christophe P. Gabriel: Methodology, Writing - review \& editing. Madhavi Srinivasan: Writing - review \& editing. Jong-Min Lee: Writing - review \& editing, Funding acquisition. Chor Yong Tay: Conceptualization, Methodology, Validation, Formal analysis, Writing - original draft, Writing - review \& editing, Visualization, Supervision, Funding acquisition. 


\section{Declaration of interests}

$\bigotimes$ The authors declare that they have no known competing financial interests or personal relationships that could have appeared to influence the work reported in this paper.

$\bigotimes$ The authors declare the following financial interests/personal relationships which may be considered as potential competing interests: 
Graphical abstract

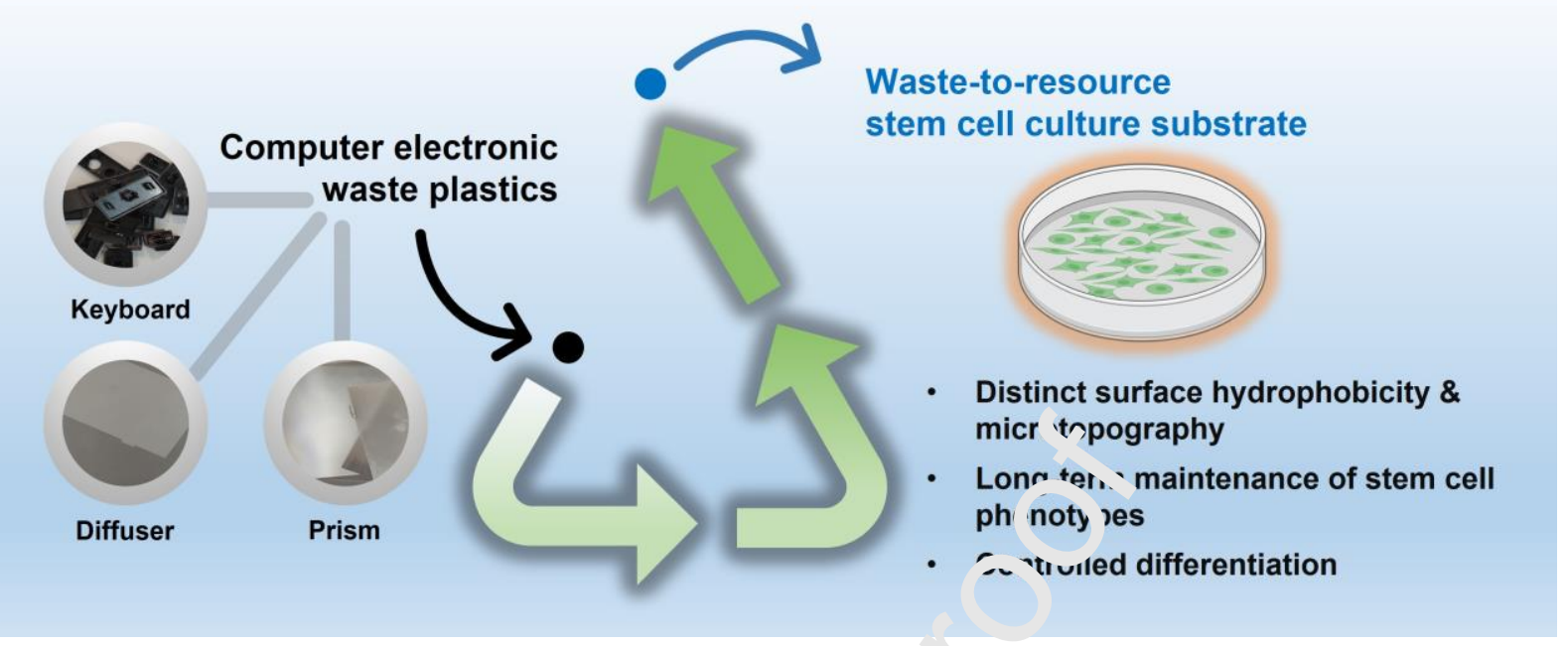




\section{Highlights}

- Innovative reuse of discarded E-plastics as cell culture substrate is presented

- Leaching of metal additives is negligible under physiological conditions

- E-plastics can support long-term self-renewability of human mesenchymal stem cells

- E-plastics surface properties profoundly impact stem cells adhesion and differentiation 